Research Article

\title{
Fabrication of a Porous Metal-Organic Framework with Polar Channels for 5-Fu Delivery and Inhibiting Human Osteosarcoma Cells
}

\author{
Li-Chun Zhao, Mei Tang, Qian-Hua Zhang, Zhi-Yi Hu, Hong-Wei Gao, Xia-Yun Liao, \\ Gang Wang, and Jing Leng $(\mathbb{D}$
}

College of Pharmacy, Guangxi University of Chinese Medicine, Nanning 530200, China

Correspondence should be addressed to Jing Leng; jing_leng666@126.com

Received 24 May 2018; Accepted 2 July 2018; Published 25 July 2018

Academic Editor: Maria F. Carvalho

Copyright (C) 2018 Li-Chun Zhao et al. This is an open access article distributed under the Creative Commons Attribution License, which permits unrestricted use, distribution, and reproduction in any medium, provided the original work is properly cited.

As an emerging kind of crystalline material, the metal-organic framework (MOF) has shown great promise in the biomedical domains such as drug storage and delivery. In this study, a new porous MOF, $\left[\left[\mathrm{Dy}_{2}\left(\mathrm{H}_{2} \mathrm{O}\right)_{3}(\mathrm{SDBA})_{3}\right](\mathrm{DMA})_{6}\right]\left(\mathbf{1}, \mathrm{H}_{2} \mathrm{SDBA}=4,4^{\prime}-\right.$ sulfonyldibenzoic acid, DMA $=N, N$-dimethylacetamide $\left(\mathrm{C}_{4} \mathrm{H}_{9} \mathrm{NO}\right)$ ), with uncoordinated $\mathrm{O}$ donor sites has been fabricated using a bent polycarboxylic acid organic linker under the solvothermal condition. The structure of the obtained crystalline product has been fully determined by the X-ray single-crystal diffraction, TGA, elemental analysis, XRD, and the gas sorption measurement. Due to the suitable window size and polar atom functionalized 1D channels, the activated $\mathbf{1}$ (1a) compound was used for the anticancer drug 5-fluorouracil $\left(5-\mathrm{Fu}, \mathrm{C}_{4} \mathrm{H}_{3} \mathrm{FN}_{2} \mathrm{O}_{2}\right)$ loading by a simple impregnation method. A moderate drug loading and $\mathrm{pH}$ dependent drug-release behavior could be observed for 1a. Furthermore, as indicated by the MTT assay, this drug/MOF composite shows low toxicity toward the human normal cells and demonstrates obvious anticancer activity against the human osteosarcoma cell line MG63.

\section{Introduction}

Being one of the most life-threatening diseases, cancer has caught the nerves of people all over the world because more and more people are suffering from cancer and die from it [1]. Currently, the most effective treatment method is still chemotherapy which relies on the anticancer drugs [2]. However, chemotherapy has always suffered some unbearable drawbacks such as nonspecific toxicity toward normal cells, poor solubility of the chemotherapy drug, and undesirable side effects [3]. In this case, great notice has been devoted to nanocarriers for anticancer drug delivery for cancer therapy, aiming at a targeted release of anticancer drugs while retarding the drug leaking into the healthy physiological environment [4]. The uncommon microenvironments at tumor sites such as low $\mathrm{pH}$ value, high glutathione (GSH) concentration, and different oxygen concentrations can be utilized to trigger drug release from the carriers.
As an emerging kind of crystalline material, the metalorganic framework (MOF) built via the assembly of organic ligands as bridges and metal ions as nodes has underwent a rapid development in the last two decades [5-7]. Recently, porous metal-organic frameworks have been proved to be very successful for drug delivery, possessing advantages such as high drug-loading capacity, suitable pore size, and strong drug-framework interaction $[8,9]$. Furthermore, the toxicity of the MOFs toward the human normal cells can be tactfully averted by selecting biocompatible metals and organic ligands. In addition, the pore walls of MOFs could be conveniently gifted polar donor sites via selecting organic ligands with polar donor sites, which could form strong frameworkdrug interaction to result in the sustainable drug-release behavior. For instance, the anticancer drug-loaded ZIF-8 nanocarriers showing $\mathrm{pH}$-sensitivite drug release have been achieved by Zhao and coworkers [10]; Kotzabasaki et al. revealed that the hydroxyl groups in IRMOF-16 could lead to 
a much improved drug-loading capacity, which outperforms many other materials targeted for the gemcitabine loading [11]. With the aim in mind of developing novel drug carriers, in this study, a new porous MOF, [ $\left[\mathrm{Dy}_{2}\left(\mathrm{H}_{2} \mathrm{O}\right)_{3}(\mathrm{SDBA})_{3}\right]$ $\left.(\mathrm{DMA})_{6}\right]\left(\mathbf{1}, \mathrm{H}_{2} \mathrm{SDBA}=4,4^{\prime}\right.$-sulfonyldibenzoic acid; Figure 1$)$, with uncoordinated $\mathrm{O}$ donor sites has been fabricated using a bent polycarboxylic acid organic linker under the solvothermal condition. Although the $\mathrm{H}_{2} \mathrm{SDBA}$ ligand has been used in building the Dy-based coordination compounds in the previous literature, none of them are porous structures [12]. The structure of the obtained crystalline product has been fully characterized by the X-ray single-crystal diffraction, elemental analysis, TGA, XRD, and the gas sorption measurement. Due to the suitable window size and polar atom functionalized $1 \mathrm{D}$ channels, the activated $\mathbf{1}$ (1a) was used for the anticancer drug 5 -Fu loading by a simple impregnation method. A moderate drug-loading and sustainable drug-release behavior could be observed for 1a. Furthermore, as indicated by the MTT assay, this drug/MOF composite shows low toxicity toward the human normal cells and demonstrates obvious anticancer activity against the human osteosarcoma cell line MG63.

\section{Experimental}

2.1. Chemicals and Instruments. All the chemicals are obtained from the regent companies and used as received. Elemental analyses $(\mathrm{C}, \mathrm{H}$, and $\mathrm{N})$ were carried out with a Vario EL III Elemental analyzer. Powder X-ray diffraction (PXRD) curves were collected on a Difrac Plus XRD Commander diffractometer at room temperature. Measurements of the UV-Vis absorption spectra were carried out in a quartz cell using a Camspec M330 UV-Vis spectrometer. Thermal gravity analysis (TGA) curves were collected using a NETZSCH STA449F3 thermal analyzer. The $\mathrm{N}_{2}$ sorption data at $77 \mathrm{~K}$ were collected on the Autosorb 1 by Quantachrome. The HPLC analysis was conducted using the 1260 Agilent chromatographic system.

2.2. Preparation of $\left[\left[D y_{2}\left(\mathrm{H}_{2} \mathrm{O}\right)_{3}(\mathrm{SDBA})_{3}\right](\mathrm{DMA})_{6}\right]$. In a $50 \mathrm{~mL}$ beaker, $\mathrm{Dy}\left(\mathrm{NO}_{3}\right) \cdot 6 \mathrm{H}_{2} \mathrm{O} \quad(46 \mathrm{mg}, 0.1 \mathrm{mmol})$, $\mathrm{H}_{2} \mathrm{SDBA}(31 \mathrm{mg}, 0.1 \mathrm{mmol})$, DMA $(6 \mathrm{~mL})$, and $\mathrm{H}_{2} \mathrm{O}(1.5 \mathrm{~mL})$

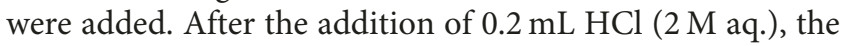
mixture was stirred for $30 \mathrm{~min}$ in the air to make a clear solution, and then, the mixture was placed in a $20 \mathrm{~mL}$ vial and kept at $90^{\circ} \mathrm{C}$ for two days. Yellow sheet crystals of $\mathbf{1}$ were obtained by filtration, washed with water, and left in the air for one day to make them dry. The yield was $46 \%$ based on the $\mathrm{H}_{2} \mathrm{SDBA}$ ligand. Elemental analysis (\%): calcd. for $\mathbf{1}$ $\left(\mathrm{C}_{66} \mathrm{H}_{84} \mathrm{Dy}_{2} \mathrm{~N}_{6} \mathrm{O}_{27} \mathrm{~S}_{3}\right)$ : C, 43.69; $\mathrm{H}, 4.67$; and $\mathrm{N}$, 4.63; found: C, 43.19; H, 4.28; and N, 4.66.

2.3. Crystal Structure Determination. The X-ray singlecrystal diffraction data of $\mathbf{1}$ were collected on the Oxford diffraction Xcalibur CCD diffractometer with Mo Ka radiation. The structural model of $\mathbf{1}$ was solved by direct methods using the SHELXT program, and the obtained model was amended using the SHELXL program. All hydrogen atoms attached to oxygen and carbon were generated

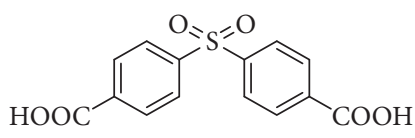

FIgURE 1: The chemical drawing of $4,4^{\prime}$-sulfonyldibenzoic acid $\left(\mathrm{H}_{2} \mathrm{SDBA}\right)$ ligand used in the construction of $\mathbf{1}$.

TABle 1: Crystal data and structure refinements for compound $\mathbf{1}$.

\begin{tabular}{lc}
\hline Formula & $\mathrm{C}_{42} \mathrm{H}_{30} \mathrm{Dy}_{2} \mathrm{O}_{21} \mathrm{~S}_{3}$ \\
\hline$M r$ & 1291.84 \\
$T(\mathrm{~K})$ & $293(2)$ \\
Crystal system & Monoclinic \\
Space group & $P 2_{1} / c$ \\
$\alpha\left(^{\circ}\right)$ & 90 \\
$\beta\left(^{\circ}\right)$ & $110.892(3)$ \\
$\gamma\left({ }^{\circ}\right)$ & 90 \\
$a(\AA)$ & $18.2117(4)$ \\
$b(\AA)$ & $21.2418(5)$ \\
$c(\AA)$ & $16.1128(4)$ \\
Volume $\left(\AA^{3}\right)$ & $5823.4(3)$ \\
$Z$ & 2 \\
$D_{\text {calc }}\left(\mathrm{g} \cdot \mathrm{cm}^{-3}\right)$ & 1.473 \\
$\mu($ Mo K $\alpha)\left(\mathrm{mm}^{-1}\right)$ & 2.719 \\
$\theta$ range $\left(^{\circ}\right)$ & 2.347 to 24.990 \\
Reflections collected & 20165 \\
$R_{\text {int }}$ & 0.0264 \\
Data number with $I \geq 2 \sigma(I)$ & 7483 \\
$R_{1}$ & 0.0251 \\
$\omega R_{2}($ all data) & 0.0558 \\
CCDC & 1844814 \\
\hline
\end{tabular}

geometrically and all non-hydrogen atoms were refined anisotropically. For the disordered nature of the DMA molecules, they could not be figured out from the structural model, so their electrons were removed from the HKL file using the SQUEEZE manipulation in the software PLATON (the total unit cell includes six DMA molecules $(48 \mathrm{e} * 6=288 \mathrm{e})$, and the SQUEEZE result reveals that 596 electrons were removed from the unit cell). This discrepancy might be owing to the different measurement conditions for the single-crystal X-ray analysis (tested after being sealed in a capillary filled with DMA) and TGA (tested after being dried in the air)). The solvents in the chemical formula of $\mathbf{1}$ were determined from the TGA curve and elemental analysis results. Relevant data concerning the crystal data and refinement parameters have been provided in Table 1.

2.4. 5-Fu Loading and Release. Twenty milligrams of activated $\mathbf{1}$ (1a) were suspended in $8 \mathrm{ml}$ of 5-Fu solutions, and then, the mixture suspensions were stirred for $72 \mathrm{~h}$ at $37^{\circ} \mathrm{C}$. Finally, 5-Fu-loaded la was obtained through centrifugation for $5 \mathrm{~min}$, washed with $\mathrm{MeOH}$, and dried at room temperature. 1a before and after the 5-Fu entrapping were characterized by PXRD. The concentration of 5-Fu in the supernatant was determined by the absorbance of 5 - Fu at $265 \mathrm{~nm}$ with the help of a calibration curve. Then, the drugloading efficiency was calculated. Drug encapsulation efficiency $=($ total amount - without loading amount $) /$ total 


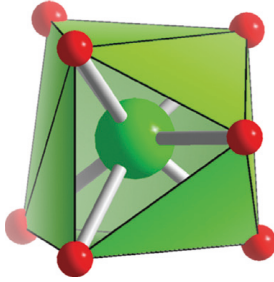

Dyl

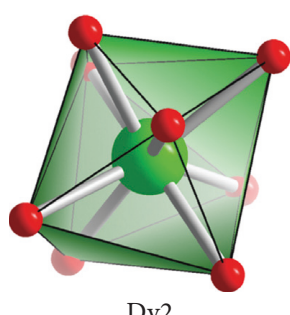

Dy2
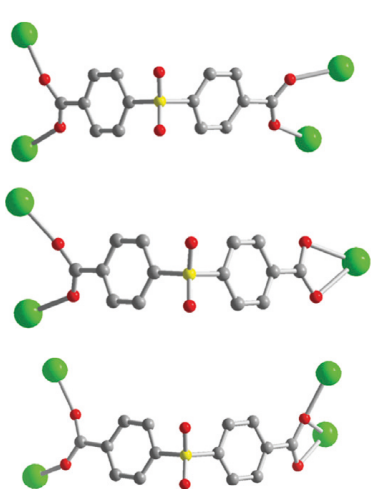

(b)

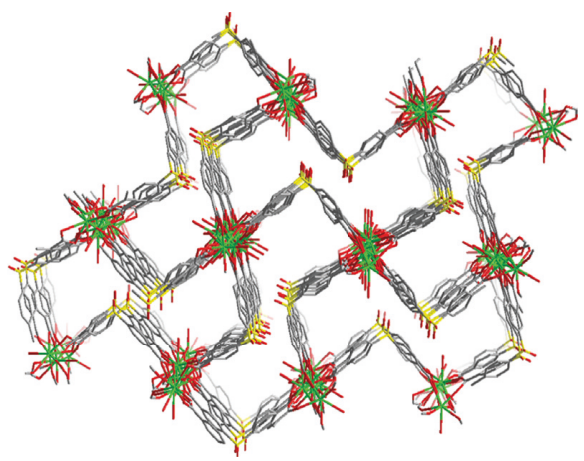

(c)

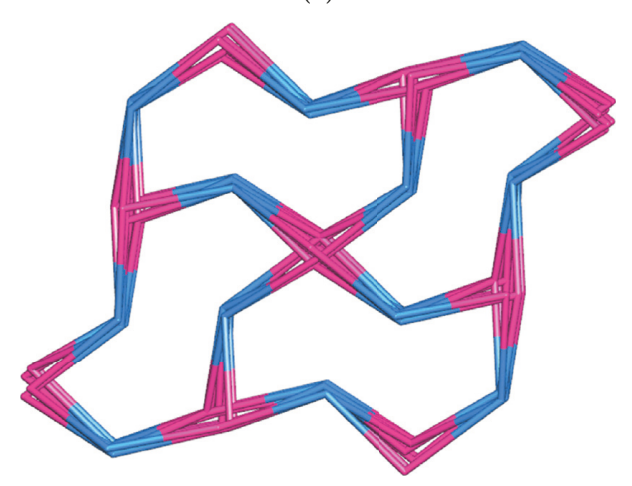

(d)

FIgURE 2: (a) The coordination surroundings for the Dy(III) ions in 1; (b) view of the binding pattern for the SDBA ligands; (c) view of the 3D network of 1; (d) 3-, 4-, 4-, 5-, and 6-connected net of $\mathbf{1}$.

amount $\times 100 \%$. The $5-\mathrm{Fu}$ release experiment was compacted in the dialysis bag. The 5-Fu-loaded crystals of 1 were soaked in the PBS solution at different $\mathrm{pH}$ values (7.4 and 5.6) at $37^{\circ} \mathrm{C}$. In each interval, $0.2 \mathrm{~mL}$ of the solution was taken out and fresh PBS with equal amount was added. Then, the $5-\mathrm{Fu}$ content was probed using the HPLC analysis.

2.5. GCMC Simulation. The adsorption process of the 5fluorouracil (5-Fu) molecule to 1a was investigated using grand canonical Monte Carlo (GCMC) simulations at $300 \mathrm{~K}$. Interactions of 5-Fu with the frameworks were described by a potential composed of van der Waals and Coulomb components. Van der Waals interactions were treated using the Lennard-Jones (LJ) potential and atomic parameters taken from the UFF force field. Coulomb interactions were calculated using atomic partial charges obtained via the charge equilibration $\left(Q_{\mathrm{eq}}\right)$ method proposed by Snurr and coworkers. Partial charges for 5-Fu molecules were calculated at the B3LYP level using the DMOL3 module. GCMC simulations were carried out with $1 \times 10^{7}$ equilibration steps and $2 \times 10^{7}$ production steps. The configuration-bias Monte Carlo method was used for trial MC moves involving insertion and deletion of 5-Fu molecules. All GCMC simulations were performed using the sorption module embedded in Material Studio 6.1.

2.6. In Vitro Toxicity Tests. The cytotoxicity toward HASM (human aortic smooth muscle) cells and MG63 cells was determined using MTT assays. The cells were seeded in a 96well microplate. After $24 \mathrm{~h}$ of cell attachment, the cells were treated and incubated with different concentrations of each complex for $48 \mathrm{~h}$. Then, $25 \mu \mathrm{l}$ of MTT solution was added into each well. After the cells were incubated for another 4 hours, $150 \mu \mathrm{l}$ of DMSO was added to each well to dissolve the MTT formazan crystals. At last, the absorbance of each well was monitored through a microplate reader.

\section{Results and Discussion}

3.1. Molecular Structure and Physical Characterization of $\mathbf{1}$. Crystallographic analysis via the X-ray single-crystal diffraction reveals that compound $\mathbf{1}$ locates in the monoclinic crystal system and $\mathrm{P} 21 / c$ space group and shows a threedimensional channel-type framework. The molecular unit is composed of two independent Dy(III) ions, three SDBA ${ }^{2-}$ ligands, and three coordinated water molecules. As plotted in Figure 2(a), eight $\mathrm{O}$ atoms from six different $\mathrm{SDBA}^{2-}$ ligands (O1, O5, O6, O7, O7A, O8, and O12) and one coordinated water molecule $(\mathrm{O} 2 \mathrm{~W})$ form the DyO8 coordination surrounding, with the Dy1-O bond distances ranging from 2.215 (3) to 2.619 (3) A; Dy2 is also an eightatom connected compound with six $\mathrm{O}$ atoms from five independent $\mathrm{SDBA}^{2-}$ ligands $(\mathrm{O} 2, \mathrm{O} 11, \mathrm{O} 13, \mathrm{O} 14, \mathrm{O} 17$, and $\mathrm{O} 18$ ) and two $\mathrm{O}$ atoms of the coordinated water molecules (O1W and $\mathrm{O} 3 \mathrm{~W}$ ), with the Dy2-O bond lengths ranging from 2.249 (2) to 2.531 (3) $\AA$. All the Dy-O bond distances 


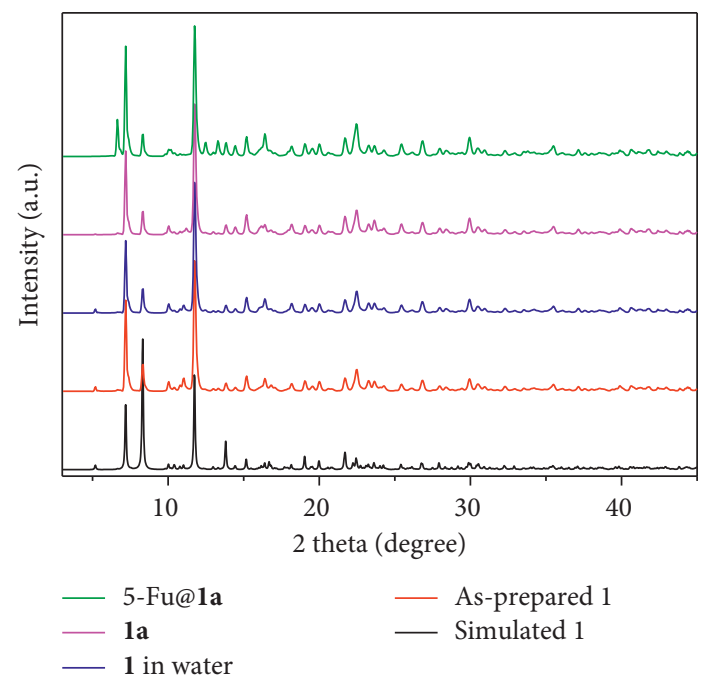

(a)

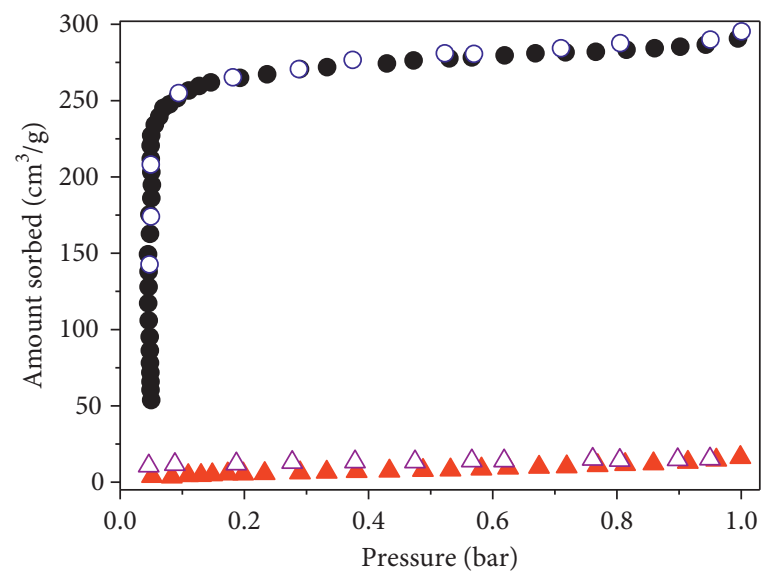

- 1a

5-Fu@1a

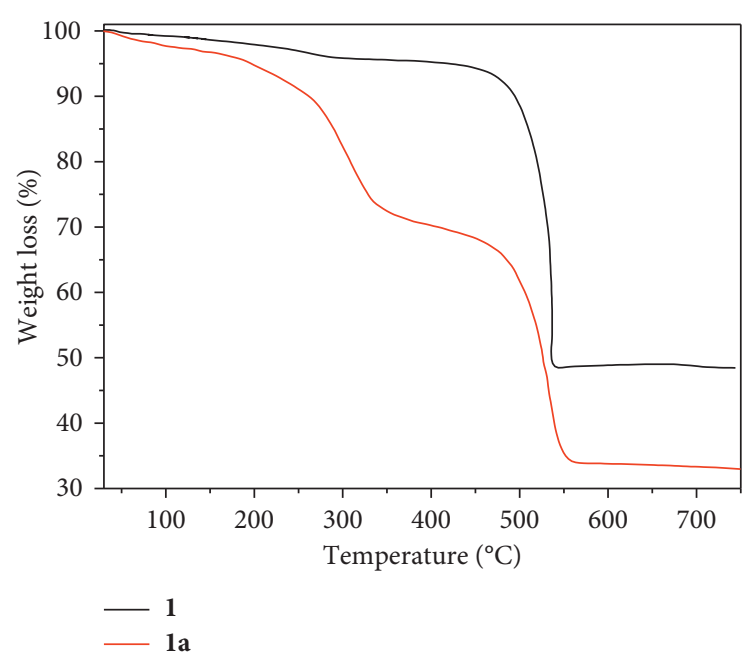

(b)

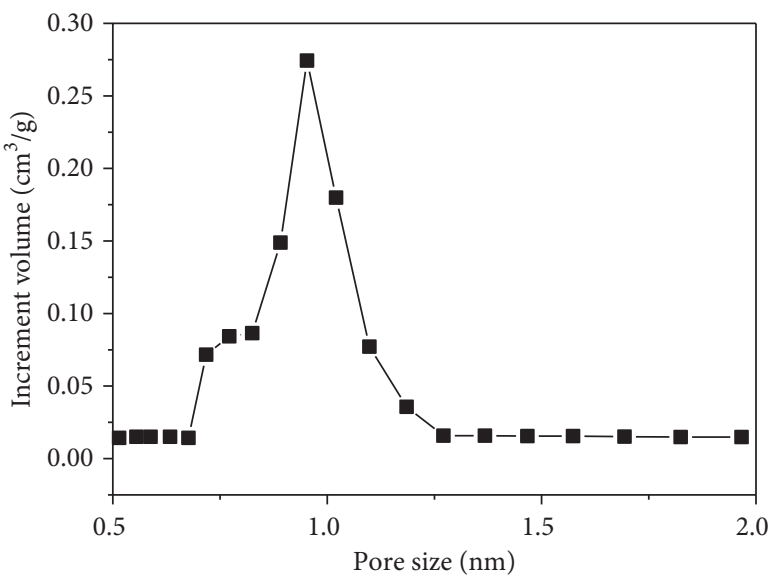

(d)

Figure 3: (a) The PXRD patterns of $\mathbf{1}$ and its different forms; (b) TGA curves of $\mathbf{1}$ and $\mathbf{1 a}$; (c) $\mathrm{N}_{2}$ sorption isotherms of $\mathbf{1}$ and $\mathbf{1 a}$; (d) hole size location of 1a derived from the $\mathrm{N}_{2}$ sorption data at $77 \mathrm{~K}$.

are comparable to those observed in the Dy-based metalorganic frameworks. The Dy1, Dy2, and their symmetryrelated atoms are held together via the syn-bridging carboxylic groups along the $a$-axis to afford the 1D secondary building unit chains with the Dy1-Dy2 separation of $5.04 \AA$. As for the $\mathrm{SDBA}^{2-}$ ligands, they exhibit three different coordination modes with the two carboxylic groups binding with one or two $\mathrm{Dy}^{3+}$ ions forming paddle-wheel units (Figure 2(b)). The SDB ligands are bent with the C-S-C bond angles ranging from 101.7 (2) to $103.6(2)^{\circ}$, which connect with the 1D SUB channels to afford the three-dimensional framework with rhombus channels (Figure 2(c)). The channels are filled with uncoordinated $\mathrm{O}$ donors site and water-occupied Dy(III) sites, which are potentially favorable for guests binding. The total effective solvent accessible volume is $2172 \AA^{3}$, corresponding to $37.3 \%$ of the cell volume. In the framework of $\mathbf{1}$, the three $\mathrm{SDBA}^{2-}$ ligands in the molecular unit could be judged as 3-,4-, and 5-connected nodes, and the two Dy(III) ions could be viewed as 5- and 6-connected nodes; so the whole framework of $\mathbf{1}$ can be abstracted as a 3-, 4-, 4-, 5-, and 6-connected topological network with the Schläfli symbol of $\{4.6 .8\}\{4 \hat{4} 2.6 \wedge 3.8 \wedge 5\}\{4 \wedge 3.6 \wedge 2.8\}\{4 \wedge 3.6 \wedge\}$ $\{4 \hat{9} .6 \hat{6}\}$, which has not been included in the TOPOS database (Figure 2(d)).

In order to determine the obtained $\mathbf{1}$ more fully in terms of phase purity and thermal stability, we carried out the PXRD measurements and TGA experiments. As shown in Figure 3(a), the good match between the simulated and experimental PXRD patterns indicates the high phase purity of the as-synthesized 1. Considering the following drug delivery experiments, the stability of $\mathbf{1}$ in water has been checked by soaking the crystalline samples of $\mathbf{1}$ in water for one day, and then, the corresponding PXRD patterns were collected, which reveal that the water surroundings could not lead to the transformation of the framework of $\mathbf{1}$, confirming its good water stability. To probe the lattice 


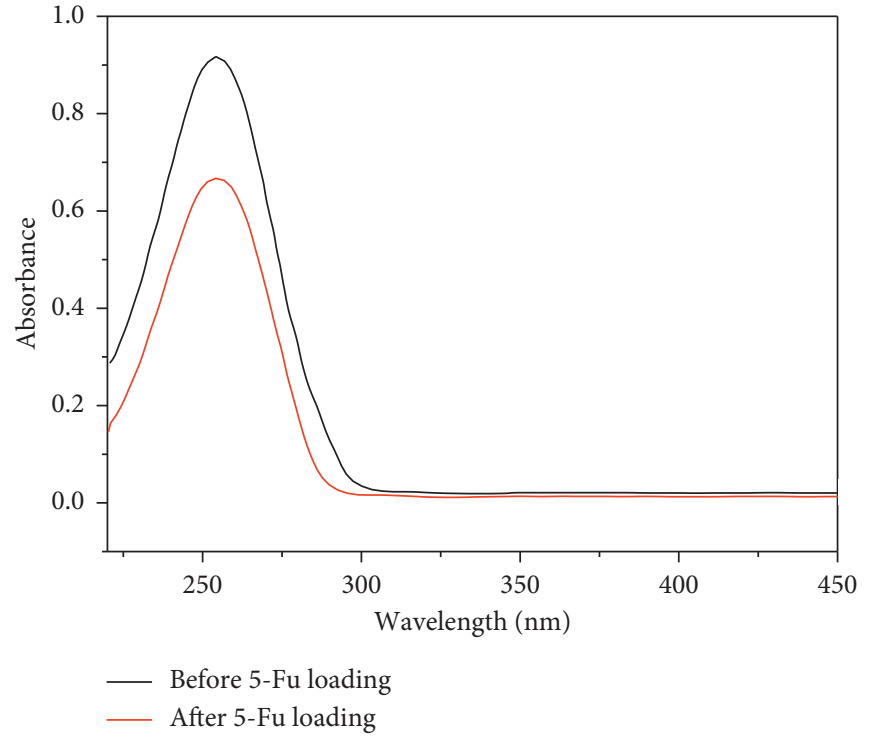

(a)

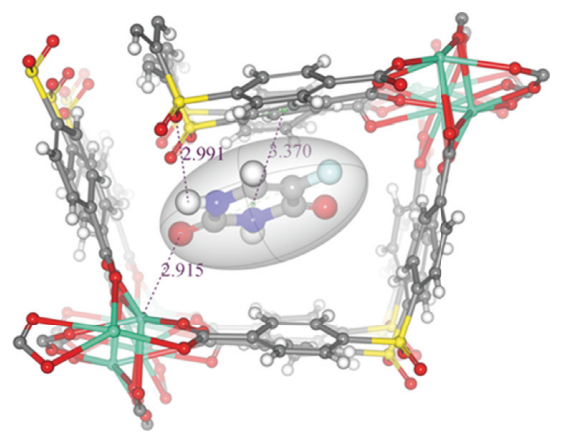

(c)

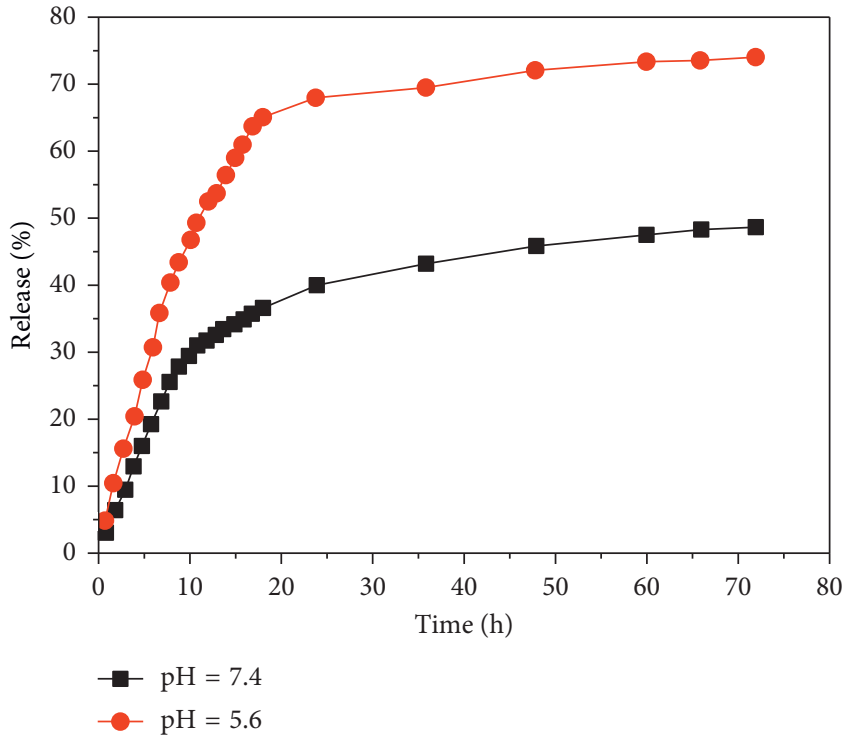

(b)

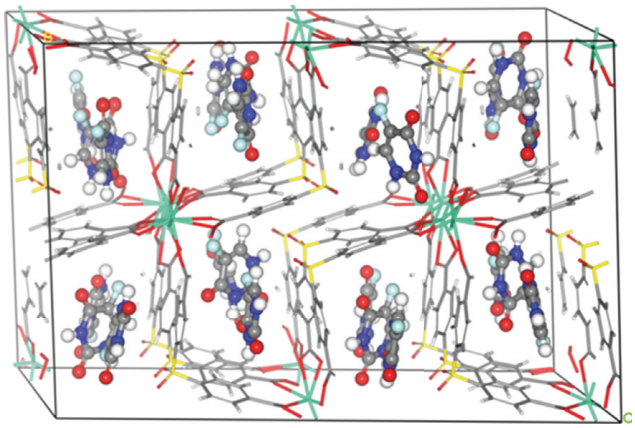

(d)

Figure 4: (a) UV-Vis spectra of the $\mathrm{MeOH}$ solution containing 5-Fu before and after loading the drug; (b) drug releasing curves under different $\mathrm{pH}$ values; (c) simulated binding site of 5-Fu in the framework of $\mathbf{1}$ at zero loading; (d) locations of the 5-Fu molecules in the framework of 1 at $37^{\circ} \mathrm{C}$ and $100 \mathrm{kPa}$.

solvents in the framework of $\mathbf{1}$, the TGA experiments were carried out (Figure 3(b)). A weight loss of $32.3 \%$ was observed in the temperature range of 25 to $429^{\circ} \mathrm{C}$, which can be attributed to the release of three coordinated water and six lattice DMA molecules. After reaching $429^{\circ} \mathrm{C}$, a sharp weight loss could be observed for $\mathbf{1}$, which indicates the collapse of the framework. To establish the permanent porosity of the solvent-free samples of $\mathbf{1}$ (1a), the as-prepared crystalline samples of $\mathbf{1}$ were soaked in the anhydrous $\mathrm{MeOH}$ for three days to exchange with the lattice DMA molecules, and then activated at $60^{\circ} \mathrm{C}$ for 12 hours. The full activation of $1 \mathrm{a}$ has been confirmed via the TGA experiments, which reveals that no obvious weight loss could be found in the temperature range of 25 to $429^{\circ} \mathrm{C}$. To determine the surface area of $1 \mathrm{a}, \mathrm{N}_{2}$ sorption isotherm was collected at $77 \mathrm{~K}$. 1a shows a type-I sorption behavior with the maximum $\mathrm{N}_{2}$ uptake capacity of $294 \mathrm{~cm}^{3} / \mathrm{g}$, which indicates complex 1 a is a microporous material (Figure 3(c)). The Brunauer-Emmett-Teller (BET) surface area was calculated to be $1222 \mathrm{~m}^{2} / \mathrm{g}$, indicating the space of 1a could house considerable amount of guest molecules. Furthermore, the hole diameter and distribution calculated from the $77 \mathrm{~K} \mathrm{~N}_{2}$ sorption method reveals a hole size distribution around $0.95 \mathrm{~nm}$, illuminating the potential of accepting guests in the pores (Figure 3(d)).

3.2. Drug Delivery Experiment. In light of its large BET surface area and suitable pore size, complex 1a has the potential for loading small guest molecules. In this work, 5fluorouracil $(5-\mathrm{Fu})$ with the molecular size of $5.3 \times 5.0 \AA^{2}$ was chosen as the guest molecules because it is a widely used drug molecule for the cancer treatment. The drug-loading experiments were carried out by impregnating of $1 \mathbf{a}(10 \mathrm{mg})$ in $5 \mathrm{~mL} \mathrm{MeOH}$ solution containing $20 \mathrm{mg}$ of $5-\mathrm{Fu}$ with consciously stirring for two hours, and then, the 5-Fu concentration in the $\mathrm{MeOH}$ solution was detected via the UV-Vis spectroscopy. As shown in Figure 4(a), there is an obvious decrease in the intensity of the UV-Vis spectrum at $254 \mathrm{~nm}$, indicating that the 5-Fu molecules are absorbed into the pores of 1 a (Figure 4(a)). The 5-Fu storage capacity is $20.6 \mathrm{wt} . \%$ (this means every $100 \mathrm{~g}$ of $5-\mathrm{Fu} / \mathbf{1 a}$ composite contains $20.6 \mathrm{~g}$ of $5-\mathrm{Fu}$ ) based on the UV-Vis spectrum 


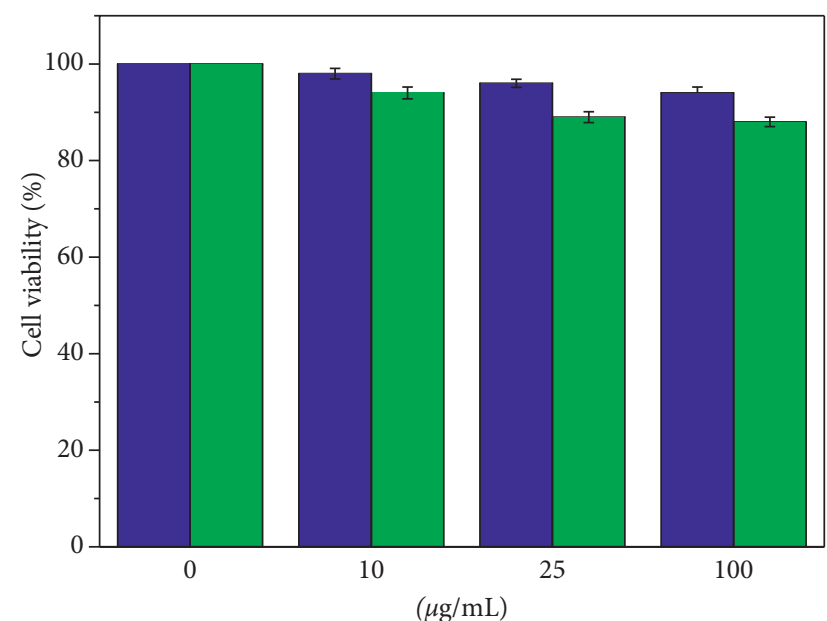

$\square$ 5-Fu@1a
$\square$ 5-Fu

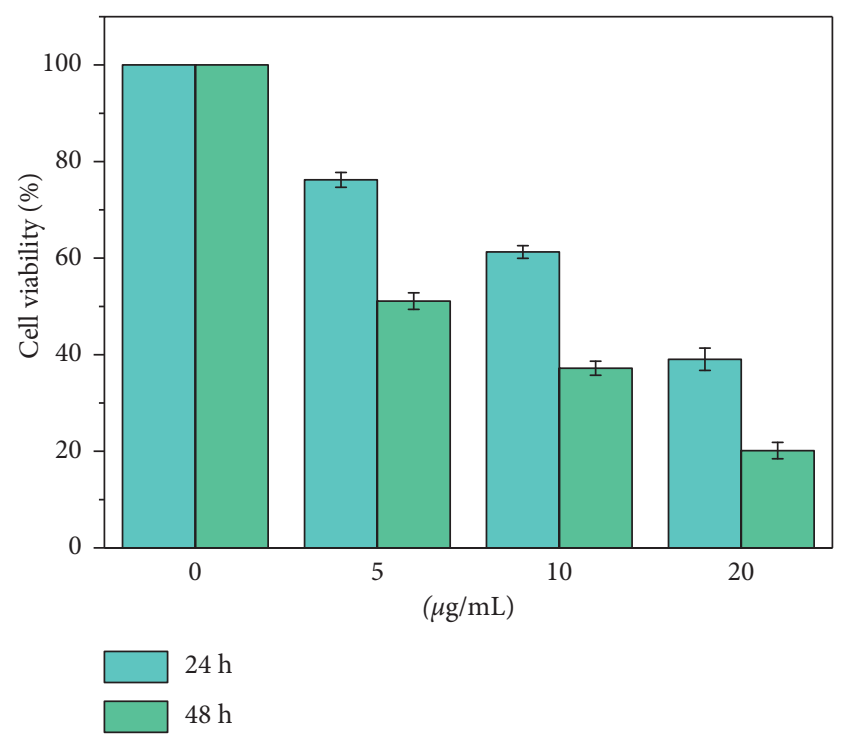

(b)

FIGURE 5: (a) HASM cell viability after exposure to 5-Fu-loaded 1a and 5-Fu at different concentrations after 24 h; (b) viability of MG63 cells after incubation with various concentrations of drug-loaded MOF at $24 \mathrm{~h}$ and $48 \mathrm{~h}$.

result. Furthermore, the $\mathrm{N}_{2}$ sorption experiment of the $5-\mathrm{Fu}-$ loaded 1a indicates that it could hardly adsorb any $\mathrm{N}_{2}$ under the given conditions, revealing that the pore spaces of $\mathbf{1 a}$ are effectively occupied by the drug molecules.

The drug sustained-release experiment was studied under different conditions $\left(\mathrm{pH} 7.4\right.$ at $37^{\circ} \mathrm{C}$ and $\mathrm{pH} 5.6$ at $37^{\circ} \mathrm{C}$ ), and the 5 -Fu released concentration was determined by HPLC. As shown in Figure 4(b), the amount of $5-\mathrm{Fu}$ released from 5-Fu-loaded $1 \mathrm{a}$ is $50 \%$ in the first $40 \mathrm{~h}$, and further increasing the time could not lead to more 5-Fu released from the carrier. The present result also indicates that the 5-Fu drug could not be completely released from the carrier under the present conditions. When the $\mathrm{pH}$ value of the PBS solution was adjusted to 5.6, it could be observed that the release rate is much faster with nearly $70 \%$ of $5-\mathrm{Fu}$ molecules being released into the solution, indicating that the $5-\mathrm{Fu}$ release is $\mathrm{pH}$ independent (Figure 4(b)). The slightly large release rate might be due to the partly decomposition of the framework. To understand the interaction between the 5-Fu molecules and the framework, the GCMC simulation was carried out. As shown in Figure $4(\mathrm{c})$, the simulated favorable binding site of $5-\mathrm{Fu}$ at zero loading indicates that the one 5-Fu molecule prefers to locate in the channel center with short $\mathrm{H}$-bond and Dy-O interactions could be observed (2.991 $\AA$ and $2.915 \AA$ ). Furthermore, besides the H-bond interactions, there also exists $\pi-\pi$ interaction between the 5 - Fu molecule and the benzene ring of the ligand with a distance of $3.370 \AA$. All these interactions contribute to the strong binding energy of 5-Fu with the framework, resulting in the long-lasting drug release. Figure $4(\mathrm{~d})$ shows the distribution of $5-\mathrm{Fu}$ molecules in the framework of $1 \mathrm{a}$ at $37^{\circ} \mathrm{C}$ and $100 \mathrm{kPa}$, which reveals that each unit cell of 1 could house 115 -Fu molecules, corresponding to $22.4 \mathrm{wt} \%$, which is near to the value calculated from the UV-Vis spectrum.
3.3. Anticancer Activity. As a drug delivery system, its cytotoxicity toward the human normal cells should be considered. With this in consideration, the cytotoxicity of the 5-Fu-loaded $\mathbf{1 a}$ and the 5-Fu were studied against the HASM (human aortic smooth muscle) cells via the standard MTT method. The HASM cells were incubated with 5-Fu-loaded 1a and 5-Fu with various concentrations, and the corresponding cell viabilities were recorded. As shown in Figure 5(a), the cell viabilities are all above 92\% under various concentrations of 5 -Fu-loaded $\mathbf{1 a}$, indicating that this drug-MOF composite has little toxicity toward the human normal cells. Furthermore, compared with the drug 5-Fu, the drug-MOF composite shows more cell viability, illuminating that the drug-MOF might possess less side effect compared with the pure drug. To probe the anticancer activity of the 5-Fu-loaded $\mathbf{1 a}$, the in vitro antitumor activity was studied against the human osteosarcoma cell line MG63 under different concentrations for $24 \mathrm{~h}$ and $48 \mathrm{~h}$, respectively. As shown in Figure 5(b), the 5-Fu-loaded 1a exhibits potent cytotoxicities against the MG63 cells, with about $60 \%$ cancer cells killed at $24 \mathrm{~h}$. Interestingly, further prolonging the experimental time could lead to more cell death, indicating the long-lasting drug release.

\section{Conclusion}

In summary, we have successfully prepared a novel porous MOF using a V-shaped polycarboxylic acid organic linker under the solvothermal condition. The as-prepared MOF is composed of $1 \mathrm{D}$ chain-like SBUs that were linked via the ligands to afford the $3 \mathrm{D}$ framework with $1 \mathrm{D}$ microporous channels running along the $a$-axis. Due to its suitable pore size and high density of $\mathrm{O}$ donor sites, it could behave as an effective carrier for the 5-Fu capture and release, and a moderate 5-Fu-loading capacity and $\mathrm{pH}$-dependent drug 
release behavior could be observed. Furthermore, the MTT assay reveals the low cytotoxicity of the 5-Fu-loaded 1a and notable anticancer activity against the human osteosarcoma cell line MG63.

\section{Data Availability}

The data used to support the findings of this study are included within this article.

\section{Conflicts of Interest}

The authors declare that there are no conflicts of interest regarding the publication of this paper.

\section{References}

[1] J. Öhlén, J. Cohen, and C. Håkanson, "Determinants in the place of death for people with different cancer types: a national population-based study," Acta Oncologica, vol. 56, no. 3, pp. $455-461,2017$.

[2] J. Bogach, O. Levine, S. Parpia, M. Valencia, L. Ruo, and P. Serrano, "Does the addition of biologic agents to chemotherapy in patients with unresectable colorectal cancer metastases result in a higher proportion of patients undergoing resection? A systematic review and meta-analysis," Journal of Gastrointestinal Surgery, vol. 22, no. 3, pp. 523-528, 2018.

[3] J. Zhou, G. Yu, and F. Huang, "Supramolecular chemotherapy based on host-guest molecular recognition: a novel strategy in the battle against cancer with a bright future," Chemical Society Reviews, vol. 46, no. 22, pp. 7021-7053, 2017.

[4] L. Wang, M. Zheng, and Z. Xie, "Nanoscale metal-organic frameworks for drug delivery: a conventional platform with new promise," Journal of Materials Chemistry B, vol. 6, no. 5, pp. 707-717, 2018.

[5] D. Rambabu, P. Negi, A. Dhir, A. Gupta, and Pooja, "Fe(III) and $\mathrm{Cu}(\mathrm{I})$ based metal organic gels for in situ drug loading and drug delivery of 5-fluorouracil," Inorganic Chemistry Communication, vol. 93, pp. 6-9, 2018.

[6] Y. Georgiou, J. A. Perman, A. B. Bourlinos, and Y. Deligiannakis, "Highly efficient arsenite [As(III)] adsorption by an [MIL-100(Fe)] metal-organic framework: structural and mechanistic insights," Journal of Physical Chemistry C, vol. 122, no. 9, pp. 4859-4869, 2018.

[7] A. C. Forse, M. I. Gonzalez, R. L. Siegelman et al., "Unexpected diffusion anisotropy of carbon dioxide in the metal-organic framework Zn2 (Dobpdc)," Journal of American Chemical Society, vol. 140, no. 5, pp. 1663-1673, 2018.

[8] J. Liu, T. Y. Bao, X. Y. Yang et al., "Controllable porosity conversion of metal-organic frameworks composed of natural ingredients for drug delivery," Chemical Communications, vol. 53, no. 55, pp. 7804-7807, 2017.

[9] X. Du, R. Fan, L. Qiang et al., "Controlled $\mathrm{Zn}^{2+}$-triggered drug release by preferred coordination of open active sites within functionalization indium metal organic frameworks," ACS Applied Materials and Interfaces, vol. 9, no. 34, pp. 2893928948, 2017.

[10] Y. Duan, F. Ye, Y. Huang, Y. Qin, C. He, and S. Zhao, "Onepot synthesis of a metal-organic framework-based drug carrier for intelligent glucose-responsive insulin delivery," Chemical Communications, vol. 54, no. 42, pp. 5377-5380, 2018.
[11] M. Kotzabasaki, E. Tylianakis, E. Klontzas, and G. E. Froudakis, "OH-functionalization strategy in metalorganic frameworks for drug delivery," Chemical Physics Letters, vol. 685, pp. 114-118, 2017.

[12] R. Łyszczek, A. Ostasz, A. Bartyzel, and A. Lipke, "Thermal, Spectroscopic and Luminescence Investigations of lanthanide(III) coordination polymers based on v-shaped $4,4^{\prime}$-sulfonyldibenzoic acid," Journal of Analytical Applied Pyrolysis, vol. 115, pp. 370378, 2015. 

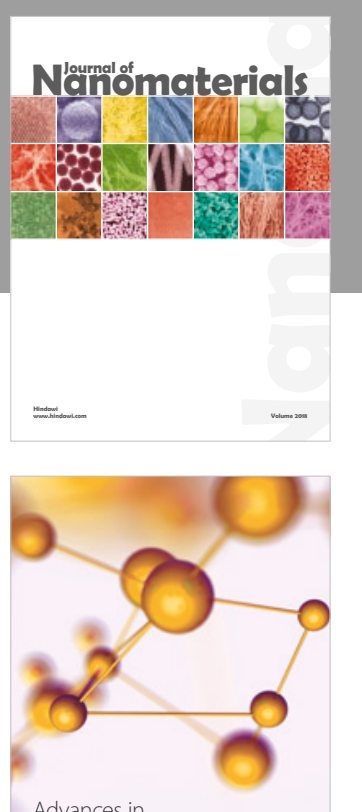

Physical Chemistry
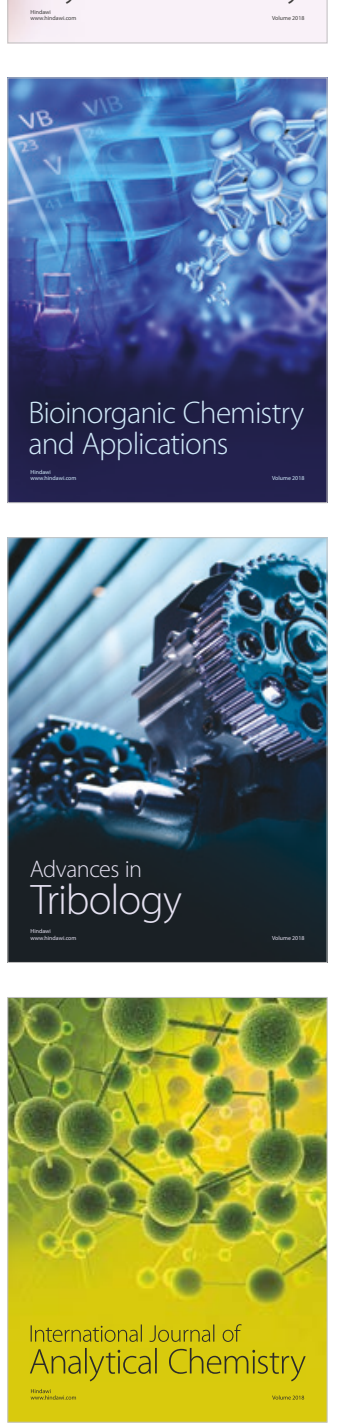

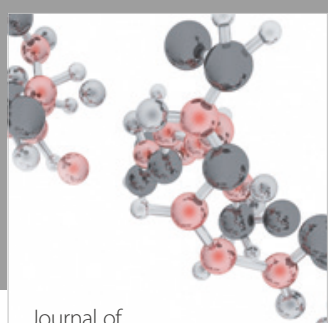

Analytical Methods

in Chemistry

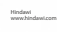

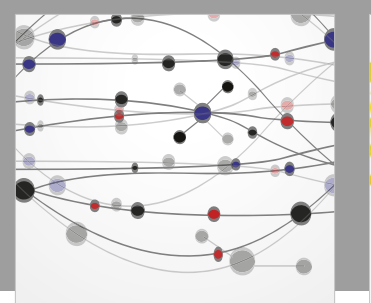

The Scientific World Journal

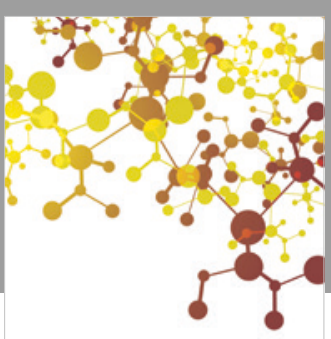

Journal of

Applied Chemistry
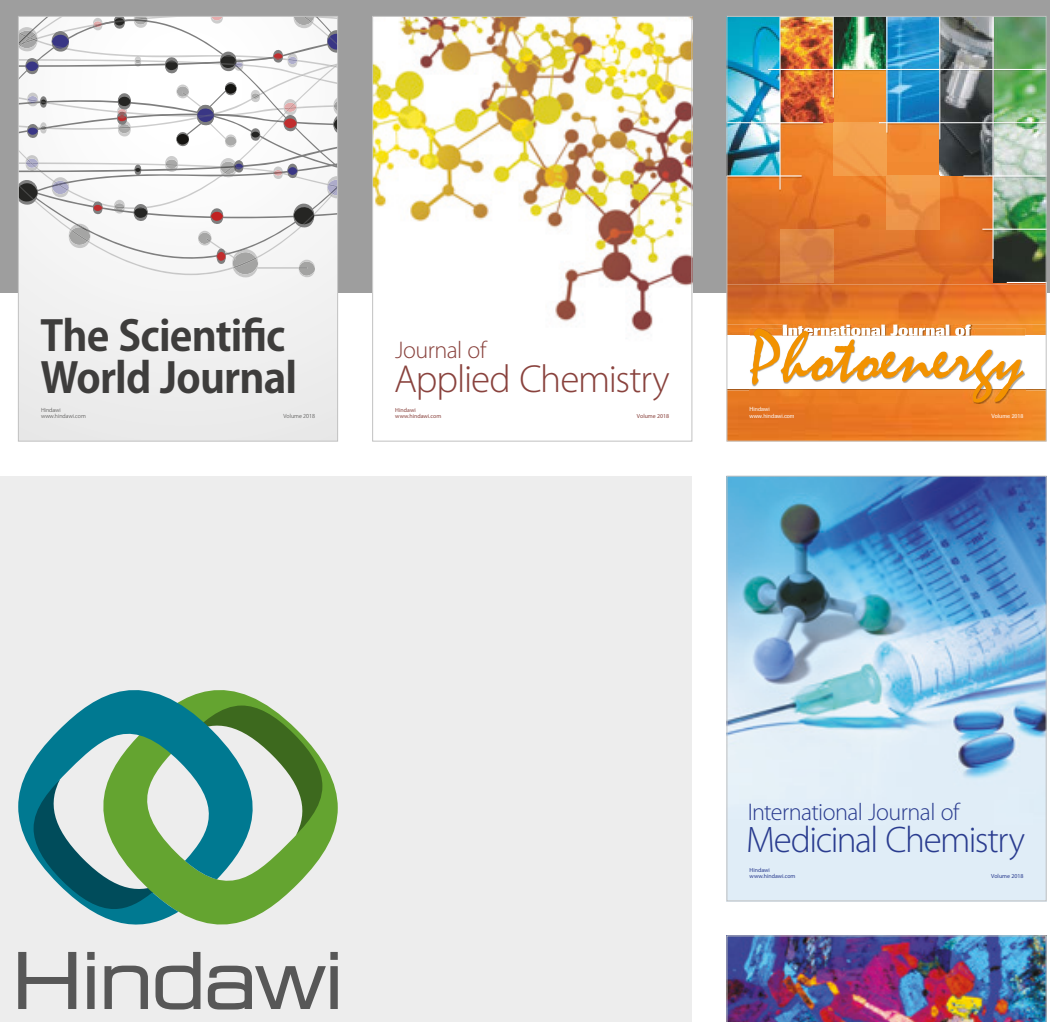

Submit your manuscripts at

www.hindawi.com
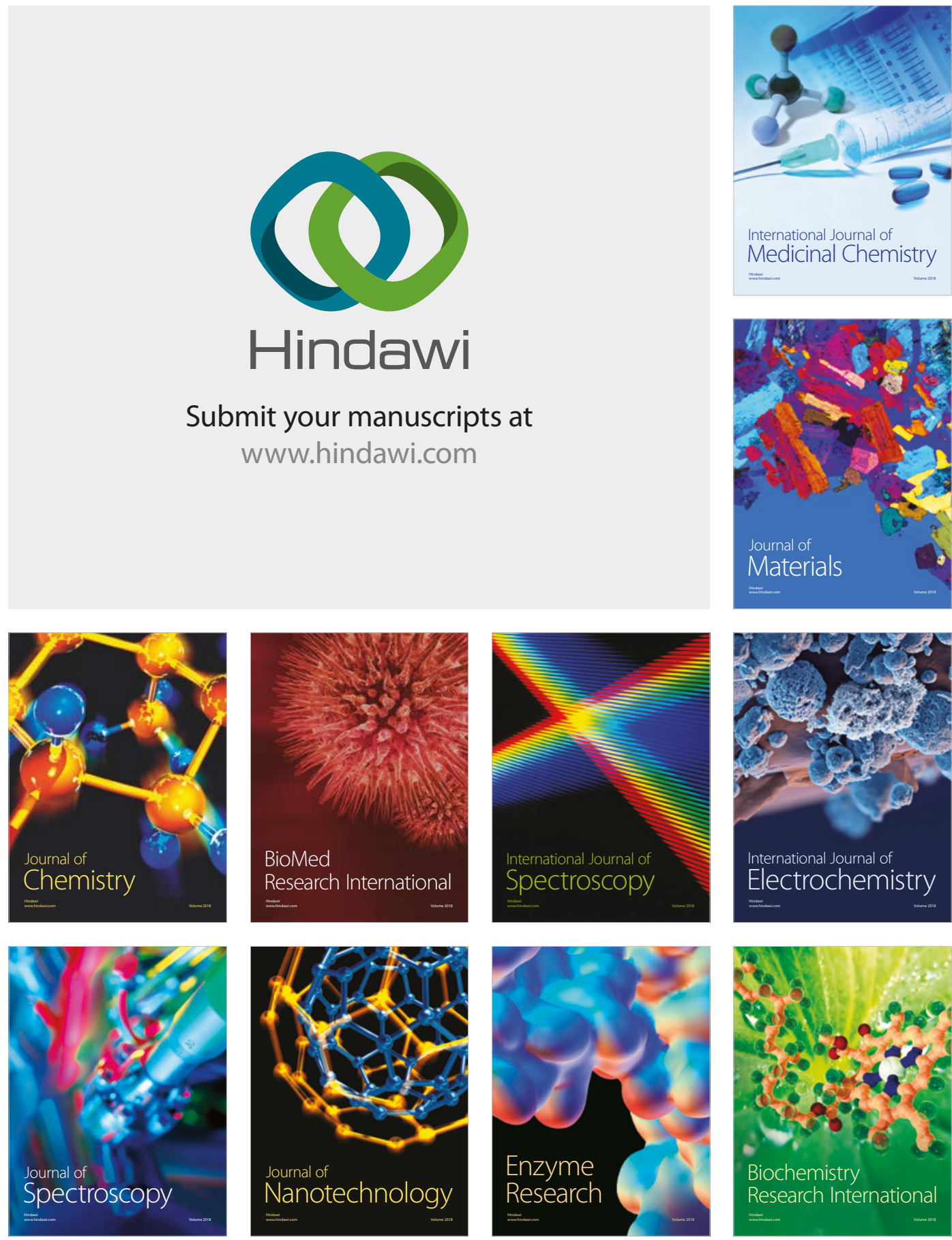
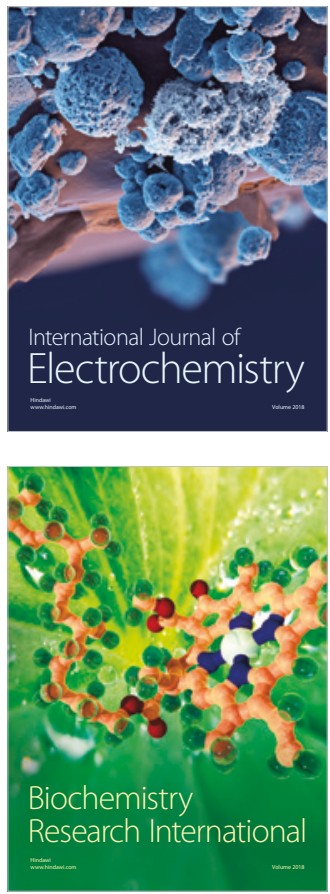